\title{
Using fourth-year medical students' reflections to propose strategies for primary care physicians, who host students in their practices, to optimise learning opportunities
}

\author{
Van Rooyen M, MMed, MBChB \\ Department of Family Medicine, University of Pretoria \\ Correspondence to: Marietjie van Rooyen, e-mail: marietjie.vanrooyen@up.ac.za \\ Keywords: medical students, learning opportunity strategies, primary care physicians
}

\section{Abstract}

Setting and subjects: Fourth-year medical students at the University of Pretoria are required to work with a primary healthcare practitioner for two weeks. After the preceptorship, reflective photo-story reports on the students' experiences and personal and academic growth are submitted.

Objectives: To identify whether the objectives of the preceptorship were met and to describe the experiences of students, the reflective reports were qualitatively analysed. A second purpose of the analysis was to propose strategies that could be implemented by the primary healthcare practitioners to optimise the learning experience of students in their practices.

Design: A qualitative approach to analyse the narratives of the photo-story reports was used. Main and subthemes were identified from the topics that were thought about. Quotes from the narratives were selected to support the themes. Each of the quotes was then scrutinised to ascertain if evidence of learning had taken place.

Results: The main themes were identified as: the impact that the visit had had on the student, the emotions that they had experienced, working with the physician, interacting with patients and the clinical care of patients. Learning was achieved under conditions that made the students feel comfortable, confident, happy and inspired; required their active participation; challenged them; inspired them to see the advantage of learning; and when feedback was given to them.

Conclusion: Strategies for use by practitioners to optimise the learning experience of students in their practices were proposed. These included active student participation, reflection, the creation of a positive environment, student participation in challenging experiences, active learning and quality time spent with patients.

(P) Peer reviewed. (Submitted: 2011-12-13. Accepted: 2012-05-12.) ๑ SAAFP

S Afr Fam Pract 2012;54(6):513-517

\section{Introduction}

"In our academic year, we seldom spend time just talking to patients. We spend even less time just listening. I was impressed by how much time the doctor spent simply chatting to our patients, gently probing to get to the root of the problem. Once a patient trusts their doctor, they will feel safe disclosing even their deepest secrets. I learnt that discussion is just as important as diagnosing". - A student

In order to be competent doctors, medical students need to be clinically proficient and to have confidence, motivation and a strong sense of professional identity. Workplacebased learning is a powerful tool that can be used to achieve these competencies, as it involves a spectrum of activities. Observations, performance and participation are important characteristics. ${ }^{1}$ Reflecting on and interpreting their interaction with patients helped students to construct meaning from the clinical experience, which in turn promoted learning. ${ }^{2}$

At the end of their fourth year, medical students at the University of Pretoria work in the practice of a primary healthcare practitioner for two weeks. This is compulsory. Students choose the practice or clinic in which they wish to work. The only proviso is that primary healthcare patients should predominantly be seen. Students can choose to work in a practice in the public or private healthcare sector, although they are encouraged to select the latter, as most of their training occurs in the public healthcare sector. The objectives of this learning activity are threefold. Firstly, it provides students with an opportunity to experience the management of patients in a primary healthcare setting. Secondly, students can investigate the differences between the private healthcare and public healthcare funding 
systems and reflect on the management of resources. Thirdly, it positions students to think and reflect on their own accountability as future healthcare workers.

At the end of this activity, students are asked to submit a reflective photo-story report on their experiences, as well as on their personal and academic growth. Another report is provided on the management of two chronically ill patients. Reflection, as stated by Sanders, ${ }^{3}$ is a process that should occur before, during and after students encounter clinical situations. The purpose of reflection for the fourth-year medical students was to develop a greater self-understanding and awareness of clinical situations in preparation for their future careers. Sanders ${ }^{4}$ stated that allowing students to use a creative medium, such as photostories, has the potential to motivate and engage them in reflective learning, on condition that sufficient guidelines are provided.

Students were provided with guidelines, theory and examples about reflection. To identify whether the stated objectives of the activity had been met and to describe the experiences of students, the reflective reports were qualitatively analysed. Evidence of reflection was the criteria for satisfactory completion of the task. Students received individual feedback about their work and an opportunity to resubmit it if it was not considered to be satisfactory. A second purpose of the analysis was to propose strategies on how to optimise the learning experience of the students at the practices of the primary healthcare practitioners for possible implementation by the latter.

\section{Method}

All 2009 fourth-year medical students submitted a hard copy photo-story report. Students were required to review their observations and experiences during the time that was spent at the practice. Each student prepared an individual presentation of between five and seven pictures. Each of the pictures represented an experience or emotion that related to their visit to the practice, as well as a narrative that described the impact that the experience had on the students. For example, a student could submit a picture of a person drowning. This might have represented the way that the student felt when he or she first arrived at the practice. The narrative needed to express how the student translated the experiences into learning, as evidenced by changed behaviour or a revision of their own approach to their practice.

The researcher carried out a document review of qualitative data that were routinely collected. Main themes were identified by the students on topics that were reflected upon. Subthemes were identified within each of the main themes. Colours were used on the hard copy reports to identify the different themes. Quotations from the narratives were selected to support the themes. The process was repeated until saturation was reached. Each of the quotes was scrutinised to establish if evidence of learning had taken place. This was reflected as an expression of new knowledge or a change in behaviour as a result of acquiring new information.

Permission was obtained from the Ethics Committee of the Faculty of Health Sciences of the University of Pretoria to use the reports of the students anonymously and retrospectively. All submitted reports were analysed.

The researcher was the only person to analyse the reports. This did not introduce bias into the study. Bias was limited because the narrative only was analysed in terms of learning having potentially taken place.

\section{Results}

The experiences upon which students reflected ranged from patient encounters to the management aspects of the practice and of patients. Themes were identified in term of areas of reflection. The different themes are presented here. Some of the quotes from the reports have been included to support each of the subthemes. Evidence of learning having taken place is underlined in the quotations.

\section{Learning about self}

During the course of the two weeks, students gained confidence in their own abilities, knowledge and training, as well as their career choice:

"I was scared, insecure and very stressed ... within the first day I calmed down and was confident in only doing my best. By the end of the two weeks I was no longer hesitant to help and I felt more confident. I learnt that the only way to progress is by throwing yourself in the deep end, making mistakes and learning from your mistakes."

Some found new motivation to study:

"Realising my lack of knowledge and practical skill I found an astounding eagerness to learn which drove me to leave my story book and start reading my physiology textbook.... in the holidays!"

The visits to the practices helped students to formulate future plans and to have more clarity about their own future responsibilities:

"I have a new found determination to study hard, apply myself and become the best doctor I can possibly be."

"It is only a matter of time until I also open up a private practice to help the community. As doctors we are both teachers and students." 


\section{Awareness of emotions}

Students reflected on feeling happy the most. They described the positive feelings that they experienced when they talked to or examined patients, when they believed that they had helped patients, or when they received approval from the general practitioners with whom they worked.

Students could easily identify the source of their happiness and could translate it into plans to continue experiencing the emotion:

"I could hardly believe how much fun I was having and how happy it made me to work with the children in the practice."

Sadness was the second emotion most dwelt upon by students. Most students used patient scenarios to explain what caused the sadness. They described their own inability to change the patient's situation and the helplessness and dissatisfaction that they experienced as a result of that.

Students could not always identify which strategies to employ in their future practice to deal with or avoid feeling sad, although they realised the necessity of coping mechanisms:

“...seeing a patient with Alzheimer's disease made me feel sad and lonely. I realised that I would have to find a way to cope with the psychological impact of certain cases and to distance myself from becoming emotionally affected by a patient."

\section{Learning from the primary healthcare practitioner}

Students were directly affected by the attitude of the primary healthcare practitioners with whom they worked, as well as their skills and problem-solving abilities:

"My admiration was for the doctor I worked with...he not only amazed me, but also inspired me to stay positive myself no matter what life throws at you. He also inspired me to want to motivate my patients to be just as positive as he is."

Workplace-based learning inspired students to think about their own future and how they envisaged their future practice.

A number of the students reflected on the fact that they felt satisfied with their career choice:

"The feeling I had when I left the practice, I must describe as optimism and hope and inspiration. I have learned so much from him, and his patients. I also feel encouraged and excited to one day be a good doctor and a good person like he is."

Primary healthcare practitioners inspired students to continuously learn and develop:

".... will inspire me to continuously develop and never allow myself or my practice to stagnate."
Students realised that they didn't have the necessary knowledge and skills yet and didn't want to impose or be in the way in the practice.

This feeling of uncertainty and unease was common:

“...the restlessness and uneasiness I feel around guns is very similar to the feeling I had the first day I started my preceptorship at the doctor. I was afraid that I would be in the way of the doctor and staff. I was afraid that they would be rude to me. I was scared that I will never be as good a doctor as the brilliant doctors in the firm I worked for."

Some students were not kept busy enough, or didn't find the patients stimulating:

"I saw a lot of the same things each day in the practice... and at times I found it a little boring."

The management and responsibilities of the practice became more evident. Students realised that considerably more than what they were accustomed to, or what they expected, was involved:

"I came to realise that for a practice to run smoothly and effectively, there should be a feeling of unity, support, friendship and respect among all the people working in the practice."

\section{Learning from patients}

From the reflections, it became evident that students learnt the most from the patients. They interacted with people from different ages and backgrounds, as well as those from different economic circumstances.

"I enjoyed meeting people from all walks of life....from old to young, I enjoyed seeing people of all ages."

They communicated on a deeper level with patients to establish how their disease impacted their lives. They had to deal with the emotions of patients and the impact that the patients' stories had on their own emotions:

"In this practice, I spent a lot of time taking patient histories. I think this was invaluable in teaching me how to communicate, as well as how to listen."

"...the stories patients told me regarding their life experiences enlightened me and taught me more about life and gave me insight into the circumstances they have been in."

"The patient's attitude surprised me and challenged me not to react in a judgemental or admonishing way, but to think of ways to explore the patient's sense of denial."

Students became aware of their own responsibility in terms of patients and the impact that they had on them as their healthcare providers: 
"We have a responsibility to each patient because at the end of the day their lives are in our hands and they trust us to give them the time and knowledge that we have."

\section{Learning about clinical management}

Being part of a management team challenged students to think about the impact of funding systems and access to health care, and the reactions of patients as a result of that:

"...regardless of the quality of health care that is available and the dedication of the healthcare team, some patients will never receive good health care due to lack of accessibility to these facilities."

The impact of the doctor-patient relationship outcome of patient care, and on the students themselves, was evident. Students had to face their own emotions when treatment failed or wasn't adhered to:

"The doctor was doing his best to help the patient, but she basically didn't give her cooperation..... this made me realise how important it is that patients also buy into their treatment and take responsibility for their bodies. Having a good doctor-patient relationship can aid in this."

By fully understanding the impact of a disease on a patient's life, the students started to recognise the importance of the patient's role in the management of the disease and of the need to be patient-centred:

"Confusion.... This is more an emotion I saw the patients experiencing rather than myself... Thus we should take the time to explain to our patients what is wrong with them. Whilst I don't have a precise formula for how to approach such a patient in the future, the key is not to react with impatience and judgement, but to empower the patient to come to their own decision by ensuring that the patient is informed in a holistic sense."

Students recognised the importance of a support system, especially the role of family, in the management plan of a patient:

"... although we might find ourselves in the sea of adversity with nothing else in sight, we can still find that small island of support through our family and friends that will keep us floating, head above water, in trying times."

\section{Discussion}

From the narratives that contained evidence that learning had taken place, a common identified theme was participation in clinical care. This was the case, even if the students didn't touch the patient, but were still involved in the discussion and management choices. This equated to taking some form of responsibility for the care of patients in the practice.
Unfortunately, very little was reported on the interaction between the students and the primary healthcare practitioners, including feedback from the latter. Increasingly, evidence supports the necessity of a practical experience to stimulate the process of learning. ${ }^{1-3,5-7}$ By participating in such activities, students are challenged to interpret what happened and to construct meaning through their personal experiences. Many different aspects influence this process, for instance prior knowledge, written information, external views and contextual factors. This new construct of meaning is then incorporated into the students' existing body of personal knowledge and needs to be tested by reflection and feedback. The role of reflection cannot be stressed enough. ${ }^{3}$ Guided reflection with a supportive mentor is necessary for students to challenge their own underlying assumptions and to consider new perspectives. ${ }^{4}$

Interacting with patients in an environment in which there is an opportunity to spend quality time with patients has the added outcome of increased awareness that the medical case has a person behind it. The literature shows, as was also evident from the reports, that students' approach to patients changed from the start of the preceptorship to become more patient-centred by the end. ${ }^{8}$

The students' reflections also showed evidence of the impact of positive feedback and reinforcement. Students need periodic personal reinforcement to keep them motivated. Often this is achieved through comments that are made by teachers and patients. ${ }^{9}$ Spending time in a practice has an enjoyment, as well as educational, value. In the literature, students reported to have changed their minds about a career choice after spending time with a surgeon in his practice. ${ }^{10}$ Confirmation of career choice was also evident in the students' reflections in this study.

\section{Conclusion}

Students reflected on a wide range of topics, including the practitioners with whom they worked, patient encounters and the clinical management of patients. Unfortunately, only a few students reflected on the practice management aspect of being a primary healthcare practitioner. Even fewer students reflected on their own accountability in the future healthcare systems of South Africa. Although students dwelled on the experiences that they had had, and the effect that these had had on them, few presented explicit evidence that learning had taken place. It is possible that students didn't contemplate these topics because they either didn't know how to do so, or simply didn't include them in their reflections. Perhaps they didn't know how to present evidence that learning had taken place. In future, it might help to make the learning objective clearer to 
students and primary healthcare practitioners and to use a rubric for the assessment of the reflections that states the criteria explicitly.

When the researcher scrutinised the reflections and experiences of the students that demonstrated that learning had taken place, the following was evident in at least one or more of the narratives:

- Students felt comfortable, confident or happy and inspired.

- Students were active participants in the practice and not just observers.

- Students were challenged, either by the situation, the patient or the primary healthcare practitioner.

- Students could recognise the advantage of acquiring new skills and knowledge.

- Students received feedback or acknowledgement from the primary healthcare practitioner or patient.

It is important to note that these findings were very subjective. Very little evidence exists on the actual behaviour of the primary healthcare practitioners. However, it was just meant as a guide to primary care practitioners who hosted students in their practice.

\section{Recommendations}

Practitioners can use the following proposed strategies to optimise the learning experience of students who visit their practices:

- Students should be allowed to actively participate in the practice as far as possible. Students need practical experience to stimulate the learning process. The more responsibility they take on, the more they are invested to learn.

- A positive environment should be created. Students are open to new information when they feel comfortable, safe, confident and inspired.

- Students should be challenged constantly with new experiences, new patient encounters and knowledge requirements. They should have an opportunity to test their own assumptions and knowledge and correct themselves where indicated. This can be achieved by constant reflection on their experiences and through the primary healthcare practitioner providing them with feedback.

- Students should be challenged with the more obscure aspects of patient management, such as the running of the practice and healthcare issues.

- Students should be helped to translate their reflections and identified learning gaps into actual learning by addressing them actively. Students often identify a knowledge gap, but don't do anything about it.

- Students should be allowed to spend quality time with patients to enable them to practise their listening and counselling skills and to get to know the person behind the patient.

- Students should be constantly motivated by being given positive encouragement and constructive feedback.

In an optimal learning environment, students can develop personally and professionally.

"I have realised how important it is to explain to the patients as clearly as possible what their conditions are, how medications work... and how important it is to comply with treatment regimes. A smile, a comfortable private room and a sympathetic ear will often aid a diagnosis just as much as a procedure. Many of the patients who I saw simply needed a gentle touch and a stethoscope to diagnose." - A student

\section{References}

1. Dornan T, Boshuizen H, King N, Scherpbier A. Experience-based learning: a model linking the processes and outcomes of medical students' workplace learning. Med Educ. 2007;41(1):84-91.

2. Teunissen PW, Scheele F, Scherpbier AJJA, et al. How residents learn: qualitative evidence for the pivotal role of clinical activities. Med Educ. 2007;41(8):763-770.

3. Sandars J. The use of reflection in medical education: AMEE guide no 44. Med Teach. 2009;31(8):685-695.

4. Sandars J, Murray C, Pellow A. Twelve tips for using digital storytelling to promote reflective learning by medical students. Med Teach. 2008;30(8):774-777.

5. Hammick M, Freeth D, Koppel I, et al. A best evidence systematic review of interprofessional education: BEME Guide no. 9. Med Teach. 2007;29(8):735-751.

6. Lindqvist SM, Reeves S. Facilitators' perceptions of delivering interprofessional education: a qualitative study. Med Teach. 2007;29(4):403-405.

7. Jakobsen F, Larsen K, Hansen TB. This is the closest I have come to being compared to a doctor: views of medical students on clinical clerkship in an interprofessional training unit. Med Teach. 2010;32(9):e399-e406.

8. Rooks L, Watson RT, Ocie Haris J. A primary care preceptorsip for first year medical students coordinate by an area health education center program: a six year review. Acad Med. 2001;76(5):489-492.

9. Reynolds HY. On becoming a doctor: a patient teaches. Acad Med. 2007;82(9):875.

10. Carter MB, Larson GM, Polk HC. A brief private group practice rotation changes junior medical students' perception of the surgical lifestyle. Am J Surg. 2005;189(4):458-461. 